Pak. j. sci. ind. res. Ser. A: phys. sci. 201457 (1) 20-31

\title{
Depositional Environments of the Bara Formation Sandstone From Lakhra Areas Sindh, Pakistan
}

\author{
Asgher Ali Daahar Hakro*a and Muhammed Atique Ahmed Baigb \\ ${ }^{a}$ Centre for Pure and Applied Geology, University of Sindh, Jamshoro, Pakistan \\ ${ }^{\mathrm{b}}$ Department of Geology, University of Karachi, Pakistan
}

(received January 3, 2012; revised Fabruary 19, 2013; accepted February 21, 2013)

\begin{abstract}
Twenty four samples of the Bara formation from east and west sections of Lakhra areas have been investigated, to interpret the environments of deposition and to propose a suitable classification for the sandstones present in the studied sediments. Values of different statistical parameters of the studied sediments grain size data, for example mean, median; standard deviation, skewness, and kurtosis were determined for plotting the cumulative curves and histograms to analyse the data. Study of the shapes, roundness and the sphericity of the grains provided valuable information regarding the environment of deposition. The 92 percentage negative and 8 percentage positive values of skewness, respectively, indicated that the studied sediments are composed of coarse grained-fine grained sediments and deposited under the high-low energy conditions of fluviatile and beach environments. The presence of abundant amounts of Quartz and $\mathrm{SiO}_{2}$ in the bulk-rock samples also suggested fluviatile/beach environments. The inclusive graphic standard deviation diagrams and the size distribution data also indicated that fine-medium grained sediments, were deposited in the study areas. Occurrence of three groups of sediments for example, sediments from lower lagoon; sediments from upper lagoon and river; and the sediments from the deadend marsh channels from the deeper parts of the basin of deposition, have been recognized. The kurtosis values indicated that studied sediments are composed of Platykurtic, Leptokurtic and Mesokurtic groups of sediments. The sandstones, present in the Bara formation of the Lakhra west and the east areas, showed the textural maturity, therefore, have been classified as sub-mature, and sub-mature to mature sandstones, respectively.
\end{abstract}

Keywords: sedimentation, cumulative curves, skewness, kurtosis, fluviatile, spherity, textural maturity

\section{Introduction}

This study describes the results which helped in interpretation of the environment of deposition and proposing a suitable classification for sandstone of the Bara formation from the Lakhra east and west areas. The studied areas are located in the western side of Khanot railway station, district Jamshoro, Sindh, Pakistan. Lakhra coalfield covers an area of about 680 Sq Km; situated between (latitudes: $25^{\circ} 30^{\prime}$ to $25^{\circ} 45^{\prime}$ $\mathrm{N}$, longitude: $68^{\circ} 00^{\prime}$ to $68^{\circ} 15^{\prime} \mathrm{E}$ ) Quadrants. Bara formation of Sindh province has been investigated, for its coal deposits, by many workers including Abbas and Atique (2005), Shah (2002; 1977) Khan (1998; 1994) and Shah (1988). These workers have contributed to the stratigraphy, coal resources and the paleontological record of the Bara formation. Prior to this study, none of the previous workers investigated the conditions of the depositional environments of these sediments.

*Author for correspondence;

E-mail: asgheralihakro@hotmail.com
The present study is first of its kind in this direction. The grain size data of the studied sediments was obtained by the sieving method for plotting the cumulative curves and histograms. Different methods of statistical analysis including the plotting of grain size data as cumulative curves and histograms were applied for collecting information regarding the environments of the deposition. Sedimentologists have used the values of the diameters of sedimentary grains, nature of sorting, values of the median, mode, kurtosis, and skewness, for the interpretation of environments of deposition of sediments.

General geology and stratigraphy. The Bara formation is composed of sandstones, shale and minor amount of siltstone; it is the oldest formation and occurs in the core of the Lakhra anticline, whereas, the Laki formation is the youngest formation of this area and occurs on the flanks of the Lakhra anticline. Structurally, the Lakhra anticline is a part of long doubly plunging anticline, which runs north-south direction and starts from 
survey of Pakistan (SOP) toposheet nos. $40 \mathrm{C} / 1$ to $40 \mathrm{C} / 4$. The geological map of Lakhra area and the stratigraphic succession, respectively, are shown in Fig. 1 and Table 1. The exposed section of the Bara formation in Lakhra areas is 20 meter thick; it is located, near Lailian Nala, and is composed of sandstone, shale and minor siltstone. The sandstones are yellow, purple, white and red in colours, loose, friable, poorly sorted, unconsolidated-consolidated, and cross-bedded (Fatmi et al., 1995). Shale is splintery, fissile and earthy in colour. Siltstone is interbedded with shale and sandstones. These sandstones are fine to medium and medium to coarse grained in texture, friable, fairly siliceous and ferruginous, poorly to moderately sorted and sub-rounded to sub-angular shapes of grains. Shale

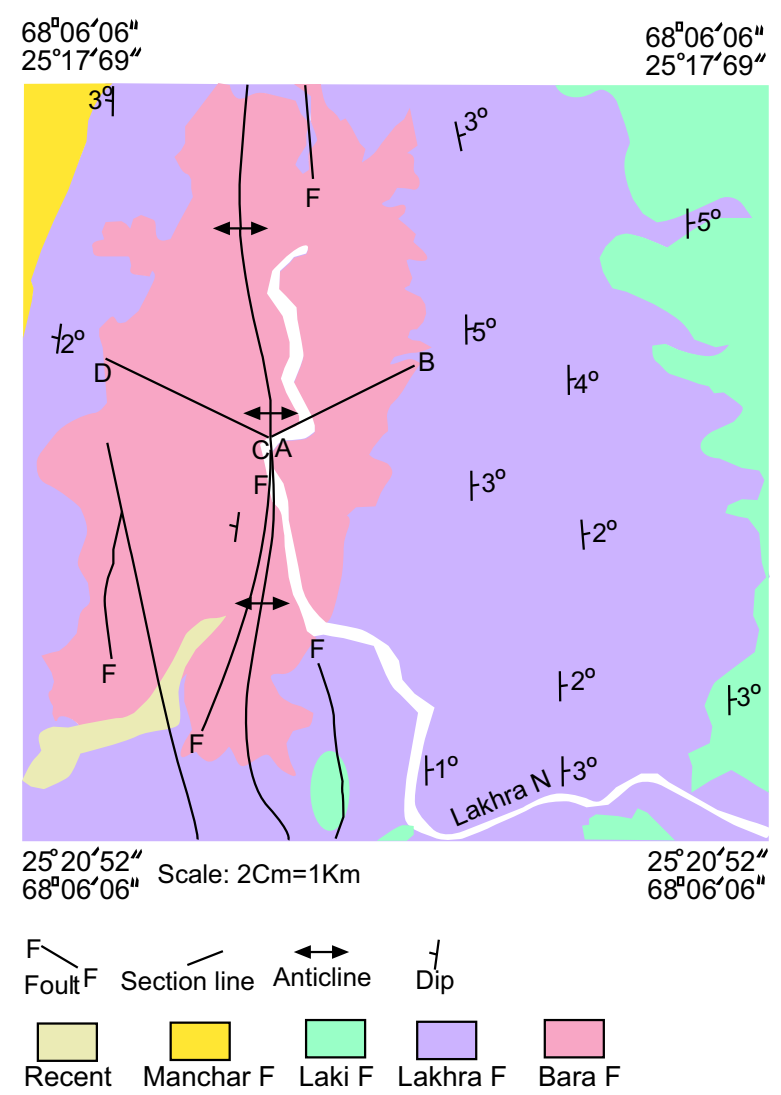

Fig. 1. Geological map of Lakhra area, Sindh.

Table 1. Stratigraphy of Lakhra area, Sindh province

\begin{tabular}{lll}
\hline \hline Age & Formation & Lithology \\
Eocene & $\begin{array}{l}\text { Laki formation } \\
\text { (sonhari member } \\
\text { and meting } \\
\text { limestone) }\end{array}$ & $\begin{array}{l}\text { limestone, sandstone, } \\
\text { shale }\end{array}$ \\
Late Paleocene & $\begin{array}{l}\text { Lakhra formation } \\
\text { Middle Paleocene }\end{array}$ & bara formation \\
\hline \hline
\end{tabular}

is brownish yellow in colour, loose, easily weathered and interbedded with sandstones.

\section{Materials and Methods}

Twenty four samples were collected from the outcrop of the Bara formation from the eastern and western flanks of Lakhra anticline. Two stratigraphic sections were measured from the eastern and western flanks of Lakhra anticline for recording the thickness of the Bara formation of Ranikot group; the section lines can be seen in Fig. 1. Both stratigraphic sections are illustrated in Fig $2(a-b)$.The measurements of these sections were completed by the Jacob's staff method. The Quardinates of Lakhra east section is (latitude: $25^{\circ} 38^{\prime} 35^{\prime \prime} \mathrm{N}$, longitude: $68^{\circ} 09^{\prime} 09^{\prime \prime} \mathrm{E}$ to latitude: $25^{\circ} 41^{\prime} 03^{\prime \prime} \mathrm{N}$, longitude: $\left.68^{\circ} 10^{\prime} 46^{\prime \prime} \mathrm{E}\right)$. The eastern section of the Bara formation started from axis of Lakhra anticline to the contact of Lakhra formation towards East along the Lailian Nala. The Quardinates of Lakhra west section is (latitude: $25^{\circ} 38^{\prime} 36^{\prime \prime} \mathrm{N}$, longitude: 68 $09^{\circ} 08^{\prime} \mathrm{E}$ to Latitude: $25^{\circ} 40^{\prime} 21^{\prime \prime} \mathrm{N}$, Longitude: $\left.68^{\circ} 07^{\prime} 02^{\prime \prime} \mathrm{E}\right)$. The western section of the Bara formation started from the axis of Lakhra anticline to the contact of Lakhra formation towards West along the Lailian Agaro Nala. The lower contact of Bara formation is not exposed in Lakhra area, whereas its upper contact is conformable with the Lakhra formation.

Section measurements. Two stratigraphic sections were measured from the eastern and western flanks of Lakhra anticline for recording the thickness of the Bara formation of Ranikot group. Both stratigraphic sections are illustrated in Fig 2 (a-b). The measurements of these sections were completed by the Jacob's staff method. The Quadrants of Lakhra east section is (latitude: $25^{\circ}$ $38^{\prime} 35^{\prime \prime} \mathrm{N}$, longitude: $68^{\circ} 09^{\prime} 09^{\prime} \mathrm{E}$ to latitude: $25^{\circ} 41^{\prime}$ ' $03^{\prime \prime} \mathrm{N}$, longitude: $\left.68^{\circ} 10^{\prime} 46^{\prime \prime} \mathrm{E}\right)$. The eastern section of the Bara formation started from axis of Lakhra anticline to the contact of Lakhra formation towards east along the lailian Nala. The Quadrants of Lakhra west section is (latitude: $25^{\circ} 38^{\prime} 36^{\prime \prime} \mathrm{N}$, longitude: $68^{\circ} 09^{\prime} 08^{\prime \prime} \mathrm{E}$ to latitude: $25^{\circ} 40^{\prime} 21^{\prime \prime} \mathrm{N}$, longitude: $\left.68^{\circ} 07^{\prime} 02^{\prime \prime} \mathrm{E}\right)$. The western section of the Bara formation started from the axis of Lakhra anticline to the contact of Lakhra formation towards west along the Lailian Agaro Nala (Fig. 1). The lower contact of Bara formation is not exposed in Lakhra area, whereas, its upper contact is conformable with the Lakhra formation.

Statistical parameters. Statistical parameters of sedimentary grains e.g., mean, median, kurtosis, 
(a) Columnar section of Lakhra East

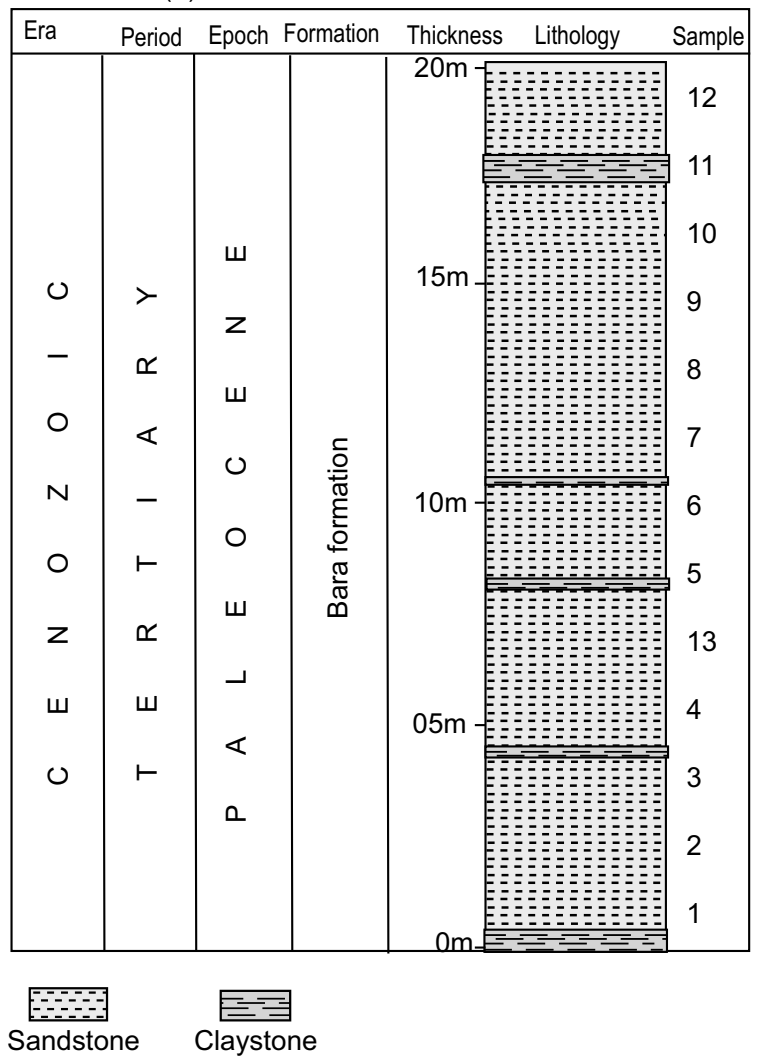

(b) Columnar section of Lakhra West

\begin{tabular}{|c|c|c|c|c|c|c|}
\hline Era & Period & Epoch & Formation & Thickness & Lithology & Sample \\
\hline $\begin{array}{l}N \\
0 \\
Z \\
w\end{array}$ & $\begin{array}{l}> \\
\propto \\
\varangle \\
- \\
\vdash \\
\propto \\
\Psi \\
\vdash\end{array}$ & $\begin{array}{l}w \\
z \\
w \\
ن \\
0 \\
w \\
-4 \\
\varangle \\
\square\end{array}$ & 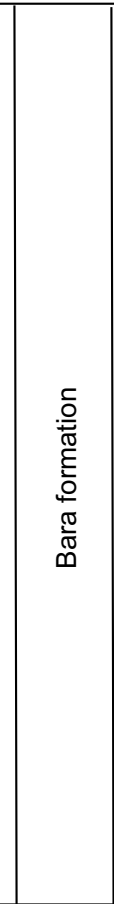 & 20m & 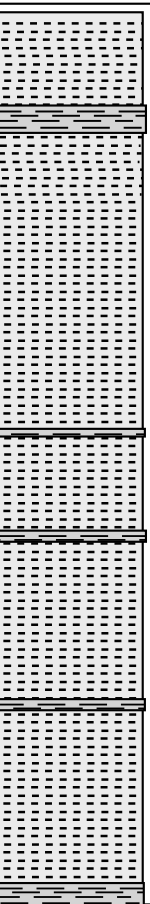 & $\begin{array}{l}11 \\
10 \\
9 \\
8 \\
7 \\
6 \\
5 \\
4 \\
3 \\
2\end{array}$ \\
\hline
\end{tabular}

Fig. 2. Columnar sections of Bara formation from Lakhra-east (a) and Lakhra-west(b) areas.

skewness and the dimensions of grains of sediments, play important role in understanding the environments of deposition of sediments. The values of statistical parameters e.g., mean, median, kurtosis, skewness, inclusive graphic standard deviation and the inclusive graphical skewness of the grain size data of studied sediments were determined, for plotting the cumulative curves and histograms. Grain size data was also plotted for the interpretation of the environments of deposition according to the diagrams given by Passega (1964) and Stewart (1958). Details of various statistical and graphical presentation methods used in the present study for the analysis of grain size of data and interpretation of the environments of deposition are described below:

Interpretation of the environments of deposition. The results of the studied sediments provided evidences which helped in the interpretation of the environments of deposition and proposing a suitable classification for the sandstones, present in the investigated sediments. Selley (1985) used the grain size data of sediments for the interpretation of the environments of deposition. According to Selley (1970), sedimentary environment is a "part of the earth's surface which physically, chemically and biologically is distinct from the adjacent areas."

Grain size analysis by sieving method. The grain size data of sediments obtained by the sieve analysis method is commonly used for knowing the distribution of the grains of sands and other sediments. The grain size analysis of the studied sediments was done by following the procedure described by Folk (1968). Thirteen samples of the friable sandstone of the Bara formation were prepared for the sieve analysis. One hundred gram of each sample was taken for sieving analysis. Each sample was dumped on white paper sheet then disintegrated with the help of fingers slowly and carefully. Afterwards, the sample was mixed with hands by corners of paper so that all particles of unconsolidated sediments were mixed with each other.

The sieving analysis of the studied samples was done by the sieve shaker method. The standard sieves were used for sieving, and the sand samples were weighed in an electronic balance; thus the sand fractions of each sieve were obtained and transferred into a container. 
Screens of all sieves were cleaned carefully, by turning the sieve face down and striking the table evenly with the rim. Screen was not touched by finger and finally it was wiped with a soft brush. A graph paper and a scientific calculator were also used. The sieve analysis was completed at the Sedimentology Lab of the Department of Geology, University of Karachi. One hundred gram $(100 \mathrm{~g})$ of each sample was used for the sieving analysis. The sieves used were of $-2 \varphi,-1 \varphi$ (granules), $0 \varphi$ (very coarse sand), $1 \varphi$ (coarse sand), $2 \varphi$ (medium sand), $3 \varphi$ (fine sand), and $4 \varphi$ (very fine sand) for sieving the samples. The sieved data of friable sandstone of the Bara formation is demonstrated by the histogram and cumulative curves (Fig. 3-4).

Study of shapes, roundness and sphericity. The shapes, roundness, and sphericity of the grains of thirteen samples were observed, under a binocular microscope by using the charts given by Zingg (1935), and Wadell (1932). Shapes of the sedimentary grains were divided into four classes e.g., spherical (equant), oblate (disc or tabular), blade and roller (rod shape) or prolate as illustrated by Zingg (1935). According to Wadell (1932) the sphericity is the ratio of the surface area of a sphere of the same volume as the particle to the actual surface. The textural characters of the grains of studied sediments have provided important clues which helped in the interpretation of the environments of deposition.

Ten gram of unconsolidated samples was placed on a glass plate which was settled on the floor of the binocular microscope below the eyepieces, and thus each sample was analysed. Majority of grains of the friable sandstone samples of the Bara formation from Lakhra sections are of equant and oblate shapes, subangular, low sphericity and the subangular class of sphericity. The use of the Power's roundness images for sand grains were facilitated by a logarithmic (rho, $P$ ), scale in which the limits of the very angular class are taken as 0.01-1.0, angular (1.0-2.0), subangular (2.0-3.0), subround (2.0-4.0), round (4.0-5.0), and the very round (5.0-6.0) $P$, as mentioned by Folk (1974). Samples from Lakhra sections showed the variable roundness of grains from subangular and sub-rounded; subrounded rounded; indicating the history of their transportation and deposition. The shapes of the samples of loosely friable sandstones were studied under binocular microscope at Department of Geology, University of Karachi, Pakistan. The grains of studied samples showed equant to equant/oblate shapes, and roundness of graind varied from subangular, to subrounded to rounded; the sphericity of grains was low, therefore, the grains fall in the class of subangular to subrounded.

\section{Results and Discussion}

The Bara formation of Lakhra anticline is composed of sandstone, shale and minor amount of siltstone; its physical characters including colours, shapes, roundness, sphericity of the grains of sandstones and shales have been described under the heading of materials. Section measurement data of the stratigraphic column of Lakhra area is shown in Fig. 2(a-b). Results of all investigated samples are shown in Table 2 and Fig. 1-7.

Graphical presentation of grain size data. The grain size data of the studied sediments was analysed by preparing histograms, plotting of cumulative curves, using the grain size data as the abscissa (X-axis) and the measure of percentage frequency as the ordinate (Y-axis). The values of the mean, median, standard deviation, skewness and the kurtosis were determined for using the methods of statistical analysis, to gain some insight regarding the environments of deposition. The histograms and the cumulative curves of the loose sediments of the Bara formation shown in Fig. 3-4 were prepared by the data of the statistical parameters shown in Table 2.

The graphical presentation of the grain size data has been considered as the most important and meaningful method, for understanding the environments of deposition of sediments (Folk,1968). Farshori (1967) used the values of skewness, kurtosis and the sphericity, for knowing the trends of the distribution of the grains, and the provenance of the sediments, of the Indus River. Duane (1964) highlighted the significance of skewness in the study of recent sediments, while, Folk and Ward (1957) described the importance of the grain size parameters in the investigation of sedimentation. Inman and Chamberlin (1955) studied the particle size distribution in near-shore sediments and according to Sahu (1964) the presence of coarse grains of clastic sediments reflect the fluidity (viscosity) factor of the depositing medium and the energy factor of the environments of the site of deposition. McCammon (1962) stated that when the values of more percentiles are read in cumulative curves, they confirm that the method is accurate. The percentile values of the loosely cemented sediments of the Bara formation from Lakhra sections were read from the cumulative curves. The values of the percentile read are $5 \%(-0.5$ to $1.1 \varphi)$, 

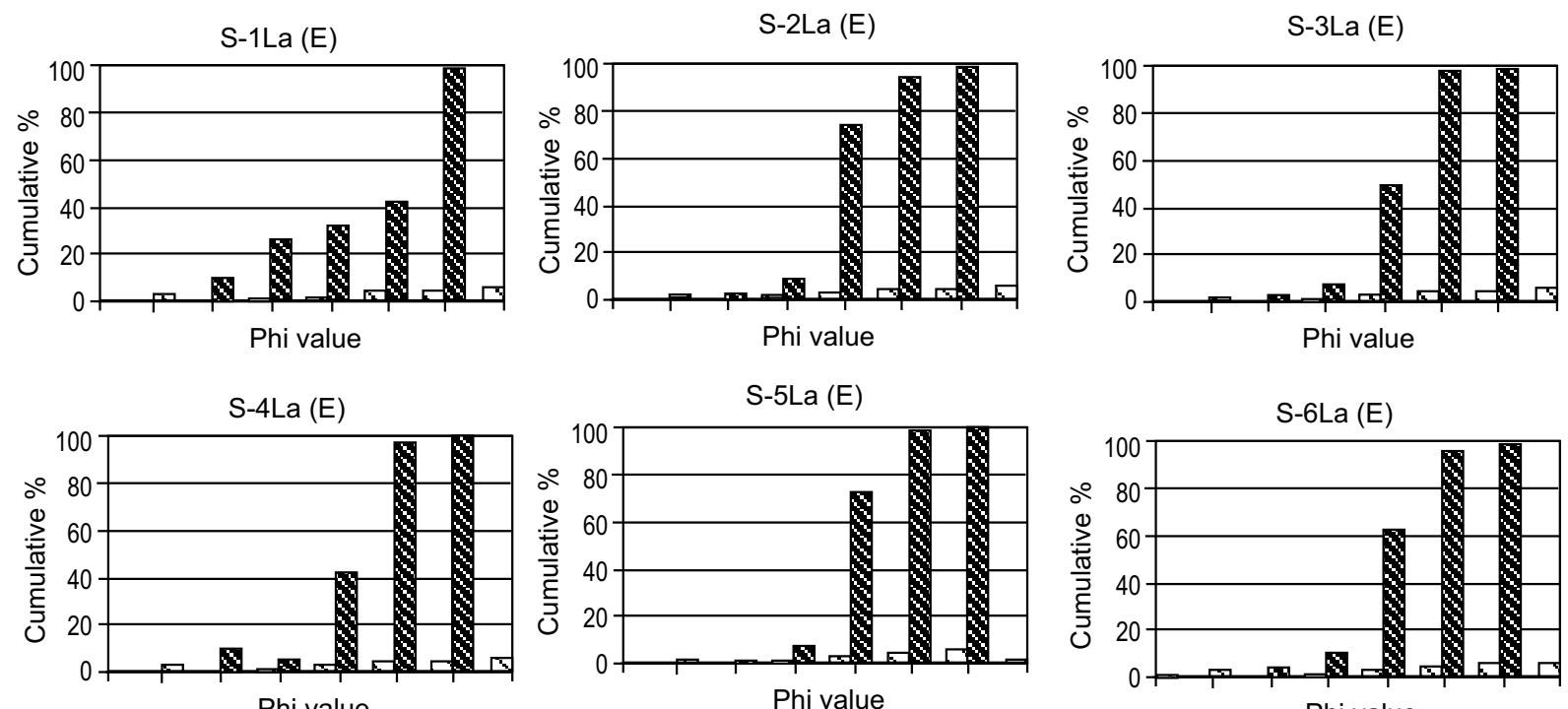

Phi value
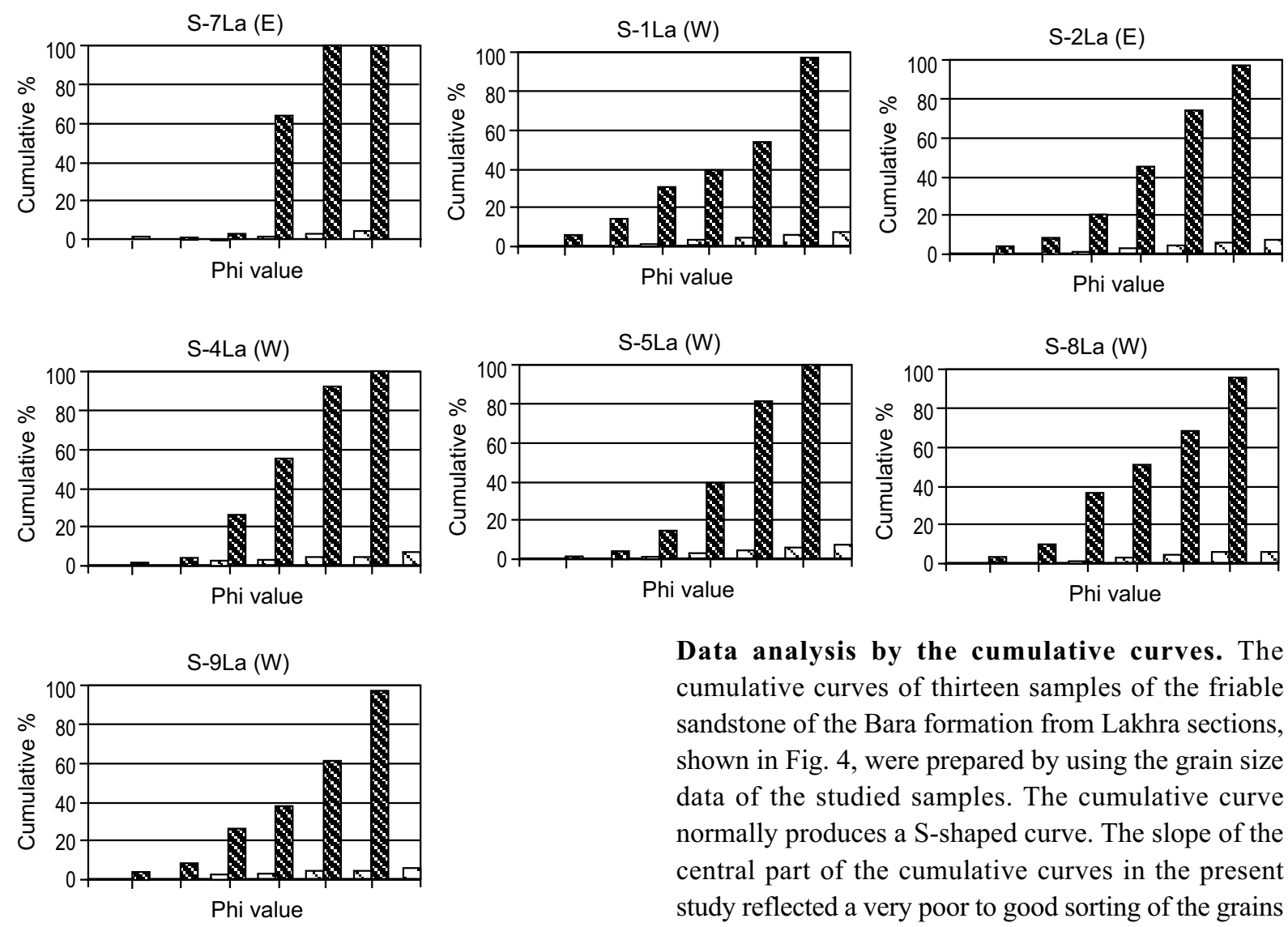

Data analysis by the cumulative curves. The cumulative curves of thirteen samples of the friable sandstone of the Bara formation from Lakhra sections, shown in Fig. 4, were prepared by using the grain size data of the studied samples. The cumulative curve normally produces a S-shaped curve. The slope of the central part of the cumulative curves in the present study reflected a very poor to good sorting of the grains by very gentle and very steep slopes, respectively. The central parts of the cumulative curves of four and nine samples, respectively, are steep and gentle. This observation indicated that the studied sediments were $16 \%$ (0.3 to $1.6 \varphi$ ), $25 \%$ (0.7 to $1.8 \varphi$ ), $50 \%$ (1.8 to 3.0 $\varphi), 75 \%$ ( 2.0 to $3.1 \varphi$ ), $84 \%$ (2.2 to $3.4 \varphi$ ), and $95 \%$ $(2.5$ to $4.2 \varphi$ ). These values were plotted for the statistical analysis of the grain size data of loose sandstones of the Bara formation from the Lakhra section. deposited under the river and beach environments, which were close to the river. The poor and good, both types of sorting exhibited by the grains further suggested that these sediments were deposited under the fluviatile 
S-1 La(E)

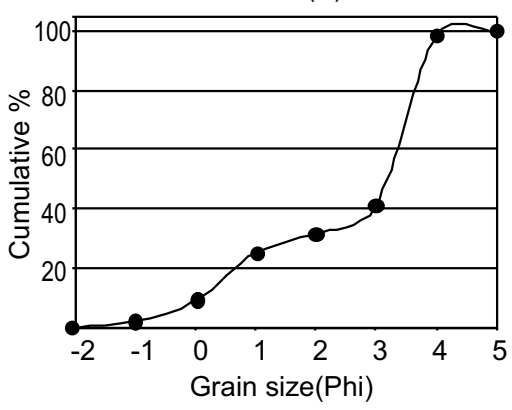

S-4 La(E)

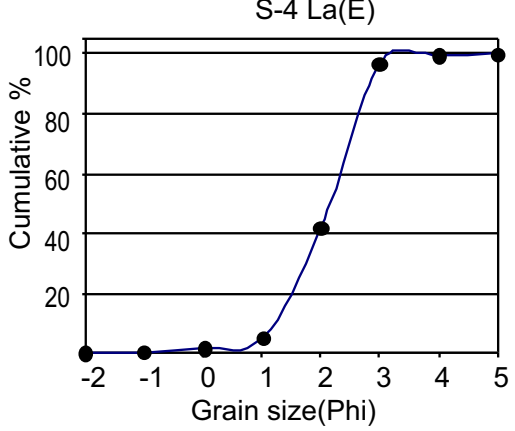

S-7 La(E)

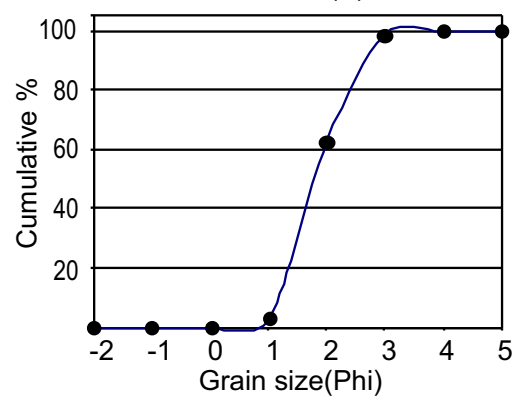

S-4 La(W)

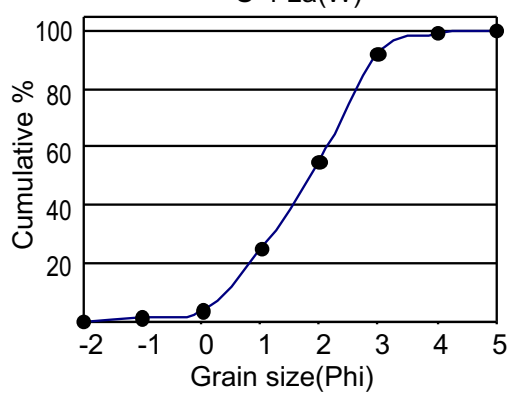

S-9 La(W)

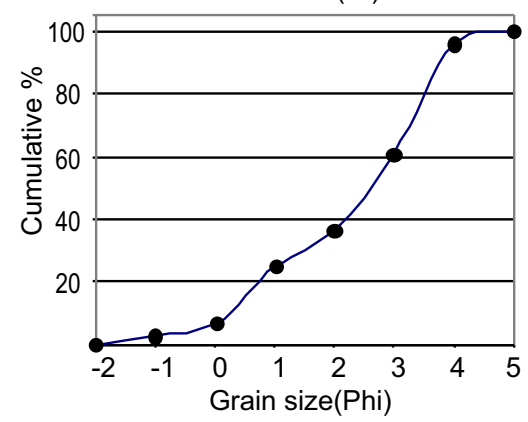

S-2 La(E)

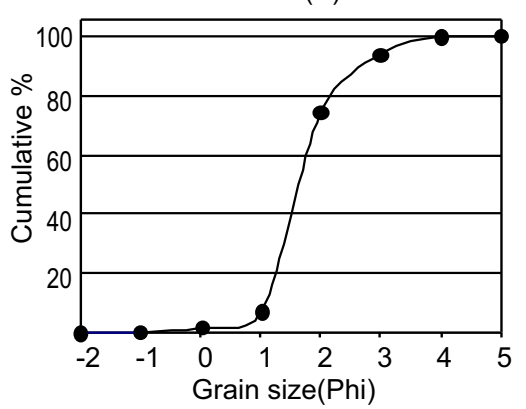

S-5 La(E)

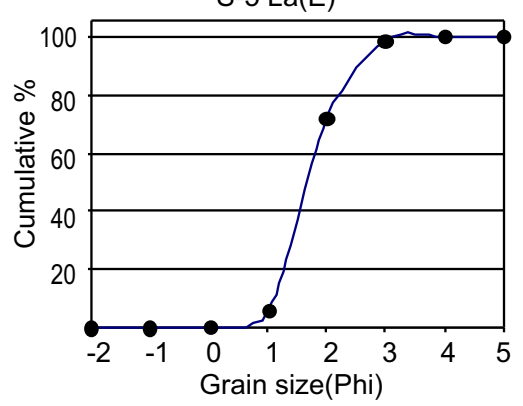

S-1 La(W)
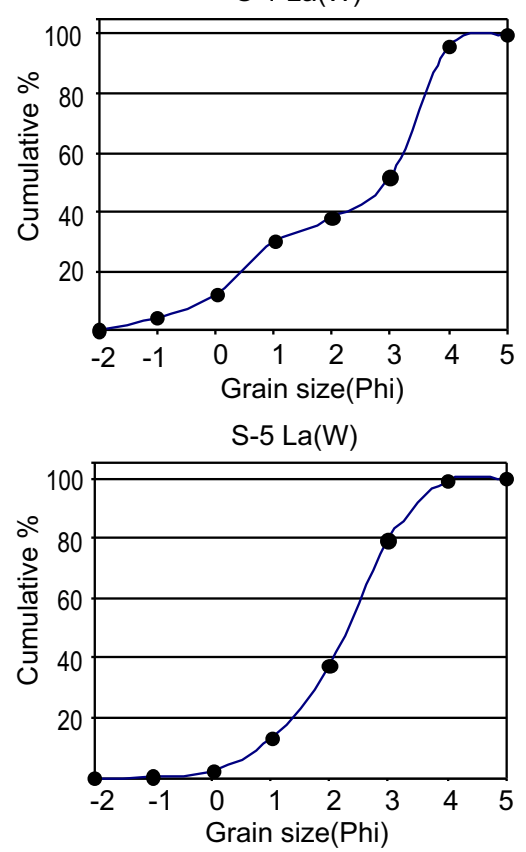

S-3 La(E)

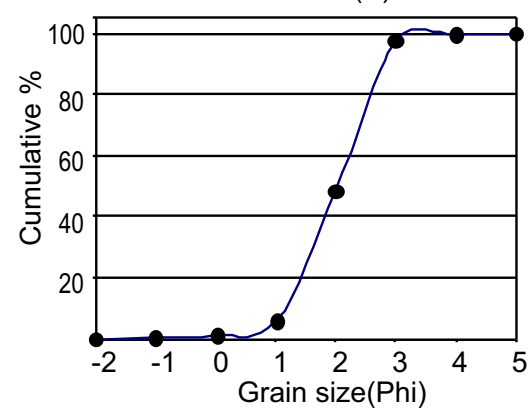

S-6 La(E)

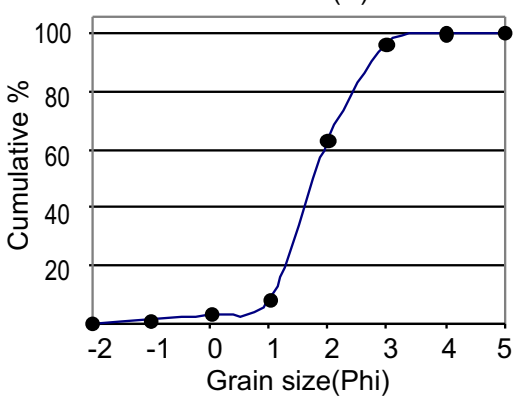

S-2 La(W)

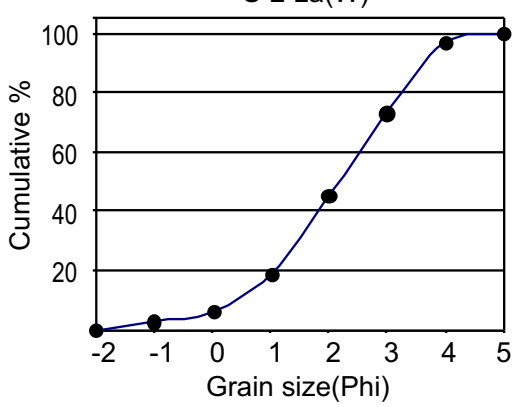

S-8 La(W)

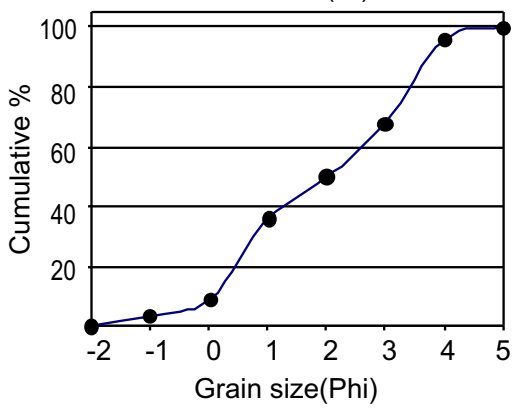

Fig. 4. Cumulative curves of Bara formation from Lakhra sections.

and beach or near ocean environments, respectively. Taking into consideration the above observations, it can be concluded that the Bara formation sediments were deposited under the fluvial, river, beach or the river waves, environments under the transitional condition, between the waves and river systems. Baqri (1997) studied the distribution of sulphur in the Paleocene 
coals of Sindh province and he reported a systematic variation and gradual increase of sulphur from east to west and concluded that Paleocene coal deposits of Sindh in the east areas were deposited under shallow continental lagoonal condition, whereas the deposition in the west area took place in deeper areas under brackish waters (deltas, estuarine) toward the Lakhra.

Analysis by graphic mean (MZ). Folk (1968) mentioned that the average graphic mean of the average size of sediments can be determined by the formula given below:

$\mathrm{MZ}=(\varphi 16+\varphi 50+\varphi 84) / 3$

The graphic mean values of the friable sandstones of the Bara formation from Lakhra areas were determined by using the above mentioned formula and the calculated values are presented in Table 2. The graphic mean values of the studied sediments, on comparison with the standard values reported by Folk (1968) clearly indicates that the dominant fraction of these sediments is composed of medium size sand particles, whereas the poorly sorted and fine grain sized sand is present in the sub-ordinate amount in the sediments of the Lakhra east area.

Analysis by median (MD). The median formula $(\mathrm{MD}=\varphi 50)$, given by Folk (1968) is commonly used for measurement in the study of sedimentology. It facilitates in the determination of the median grain size. The application of this formula in the present study indicated that particles of half of the samples by weight are coarser than the median, and the remaining half are finer. It is the diameter corresponding to the $50 \%$ mark on the cumulative curve and may be expressed either in $\varphi$ (MD $\varphi$ size). The median values of the studied sediments are tabulated in Table 2.

Analysis by inclusive graphic standard deviation or sorting. The inclusive graphic standard deviation or sorting formula, $\sigma \mathrm{I}=(\varphi 84-\varphi 16) / 4+(\varphi 95-\varphi 5) / 6.6$, formula given by Folk (1968) is one of the most useful methods to determine the nature of the sorting of sediments; its application provides information regarding the effectiveness of the depositional medium in separating the grains of different classes.

The results of the inclusive graphic standard deviation of studied sediments (Table 2) shows that the values of sorting of loose cemented sandstone of the Bara formation from Lakhra sections, have showed a range
Table 2. Statistical parameters of Bara sandstones from Lakhra sections

\begin{tabular}{llllll}
\hline \hline Sample & \multicolumn{3}{l}{ Graphic Graphic } & Sorting & Skewness \\
& mean & median & & & \\
\hline $1 \mathrm{La}(\mathrm{E})$ & 2.36 & 3 & 1.2 & -1.6 & 1.34 \\
$2 \mathrm{La}(\mathrm{E})$ & 1.83 & 1.8 & 0.6 & 0.06 & 2.21 \\
$3 \mathrm{La}(\mathrm{E})$ & 1.93 & 2 & 0.5 & -0.02 & 1.72 \\
$4 \mathrm{La}(\mathrm{E})$ & 1.98 & 2 & 0.4 & -0.6 & 2.50 \\
$5 \mathrm{La}(\mathrm{E})$ & 1.9 & 1.9 & 0.4 & -0.05 & 2.46 \\
$6 \mathrm{La}(\mathrm{E})$ & 1.9 & 1.9 & 0.5 & -0.1 & 2.55 \\
$7 \mathrm{La}(\mathrm{E})$ & 1.9 & 1.9 & 0.3 & -0.09 & 1.43 \\
$1 \mathrm{La}(W)$ & 2.16 & 3 & 1.6 & -0.5 & 0.89 \\
$2 \mathrm{La}(W)$ & 2.13 & 2.3 & 1.4 & -0.3 & 1.31 \\
$4 \mathrm{La}(W)$ & 1.7 & 1.9 & 0.8 & -0.03 & 1.75 \\
$5 \mathrm{La}(W)$ & 2.26 & 2.6 & 0.9 & -0.4 & 0.89 \\
$8 \mathrm{La}(W)$ & 1.9 & 2 & 1.5 & -0.1 & 0.90 \\
$9 \mathrm{La}(W)$ & 2.26 & 2. & 1.5 & -0.4 & 1.11 \\
\hline \hline
\end{tabular}

from 0.3-1.2 $\varphi$ indicating that these sediments are mixture of well sorted to moderately sorted to well sorted and poorly sorted grains, whereas, the samples from Lakhra west section shows a range from 0.8-1.6 $\varphi$ indicating that these sediments are poorly to moderately sorted. These results supported a fluviatile system of deposition for the studied sediments. Nevertheless, the presence of well sorted sediments also supported the beach or near river type of environments of the deposition. River sand generally show poor sorting of grains than the beach sand, due to lower energy conditions, prevailing in rivers. The poor sorting of the grains of river sands due to the presence of fine grains are also distinguished by the positive skewness. A perfect discrimination between the beach and the river sands can be made by plotting the standard deviation (sorting) data against the skewness data. Dune sand, being finer than the coarser sand of beach, is also positively skewed. Friedman (1961) mentioned that due to the competence of the ocean waves, which are greater than that of the wind, the beach sand grains are coarser. The sorting of grains of the Bara formation sediments, from the Lakhra sections further indicated heterogeneity of the sediments and the depositional environments.

Analysis by inclusive graphic skewness (SKI). The skewness is the measure which depicts the uniformity of the distribution of sediments. The zero value of skewness is taken as a normal distribution of sediments which means that the cumulative curve is symmetrical and does not possess any tail. If the finer fraction is present in excess than the coarser fraction, in that case 
the value of the skewness is generally positive (Phi value) and in the reverse situation the skewness value is negative (Phi value + ). In the present investigation the inclusive graphical skewness values were determined by Folk'sformula (1968) as given below:

$$
\mathrm{SKI}=\frac{\varphi 84+\varphi 16-2(\varphi 50)}{2(\varphi 84-\varphi 16)}+\frac{\varphi 95+\varphi 5-2(\varphi 50)}{2(\varphi 95-\varphi 5)}
$$

The fluviatile environments of deposition of sediments are indicated by the sediments which are composed of large amount of clay and silt, commonly carried by rivers and showing the positive values of skewness. The skewness and the inclusive graphic skewness values of the loose cemented sandstone of the Bara formation from Lakhra east and west sections are ranging from 0.06 to -1.6 Phi. The $92 \%$ negative values of skewness indicated that coarse grained sediments were deposited under high energy depositional environments; only one sample showed $8 \%$ positive value of skewness which indicated deposition of fine grained sediments, under low energy condition. These observations indicated that the environments of deposition of the Bara formation were fluviatile. The beach sands according to Boggs (1987) tend to be negatively skewed because the fine sediments are winnowed out of beach sediment and are removed owing to bidirectional transport by the currents of unequal velocity than the ebb flow back down the beach, therefore, the fine particles may be removed by the return flow, leaving a negative skewed population of well sorted, coarser grains. The above discussion also supports that the environments of deposition of the studied sediments were more close to the beach and river depositional environments.

\section{Analysis by graphic kurtosis (KG).}

$K G=\varphi 95-\varphi 5 / 2.44(\varphi 75-\varphi 25)$

The values of graphic kurtosis of the loose cemented sandstone of the Bara formation from Lakhra sections as showed in Table 2, were determined by using the formula mentioned above (Folk, 1968). The kurtosis values showed a range from $0.89-2.55$ indicating that these sediments are very platykurtic to mesokurtic to leptokurtic to very leptokurtic. The kurtosis data of the Bara formation sediments showed uniform distribution with negative excess, normal distribution and the positive excesses distribution, respectively. This data showed good agreement with the data given by Folk (1968).
Analysis by the Stewart diagram. Stewart (1958) plotted the values of median against the values of skewness and the standard deviation of the river sediments which were deposited under the wave dominant zones and the quiet water environments. $\mathrm{He}$ recognised three different types of sediments within the lagoon, sediments deposited by wave processes; rivers process, and the slow rate of deposition, from the quiet water. He also described the details of the relationship of the median against the Phi deviation and skewness and the Phi median diameter to the Phi deviation measure and the Phi skewness for his sediments.

The values of median, standard deviation and the graphic skewness of grain size data of loosely cemented friable sediments of the Bara formation from Lakhra sections of southern Sindh showed in Table 2, were plotted according to the diagram given by Stewart (1958). Fig. 5a-5b and 6a-6b, show the plots of the grain size data of the friable sandstone. Figure 5a, shows that the plotted samples were deposited under river and Fig. 5b, indicates that these samples were deposited between the boundary of rivers and waves, dominating in the wave's portion. The under discussion sediments according to this figure were deposited under the fluvial depositional environments near the sea. Fig. 6a, also shows that sediments were deposited under river between the boundary of river and waves condition.

Analysis by Passega (1964) diagram. The statistical parameters of the grain size data of the Bara formation sediments, varies from -2.0 to 0.3 (4000 to 832 microns) and the mounts of median varying from 1.9 to 3.0 (266.6 to 125 microns); were plotted according to the Passega (1964) diagram for getting more information regarding the environments of deposition. The values of one percentile and the median of the sediments of Lakhra sections (which are in phi scale), were converted into microns for using in the Passega diagram. Figure 7 shows the grain size data of loosely friable cemented sediments of Lakhra sections plotted according to Passega (1964) diagram. This plot has provided sedimentological evidences which supported the fluviatile environments of deposition. According to Passega (1964) the ratio of the one percentile (C) to the median diameter $(\mathrm{M})$ could be used as an indicator of the dynamics of the depositional environments, the (CM) patterns on a logarithmic diagram are characteristic of the depositional agent. 

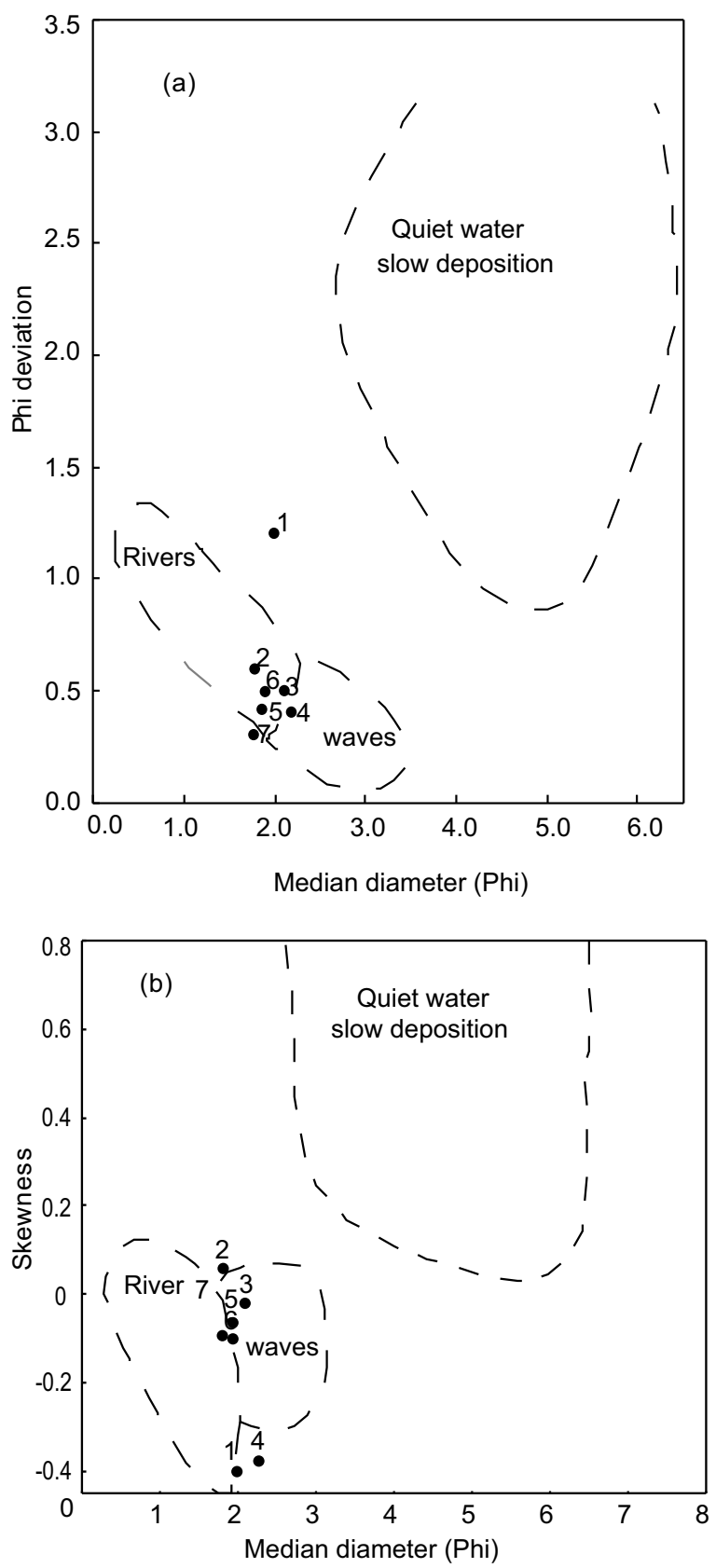

Fig. 5. Bivariate plots of loosely cemented sediments of Bara formation from Lakhra east section (after Stewart, 1958).

The data of the Bara formation plotted according to Passega (1964) diagram displayed that the studied sediments were deposited between the river and beach environment conditions.

Classification of Bara formation sandstone. In the present investigation, besides the interpretation of the depositional environments of studied sediments, an
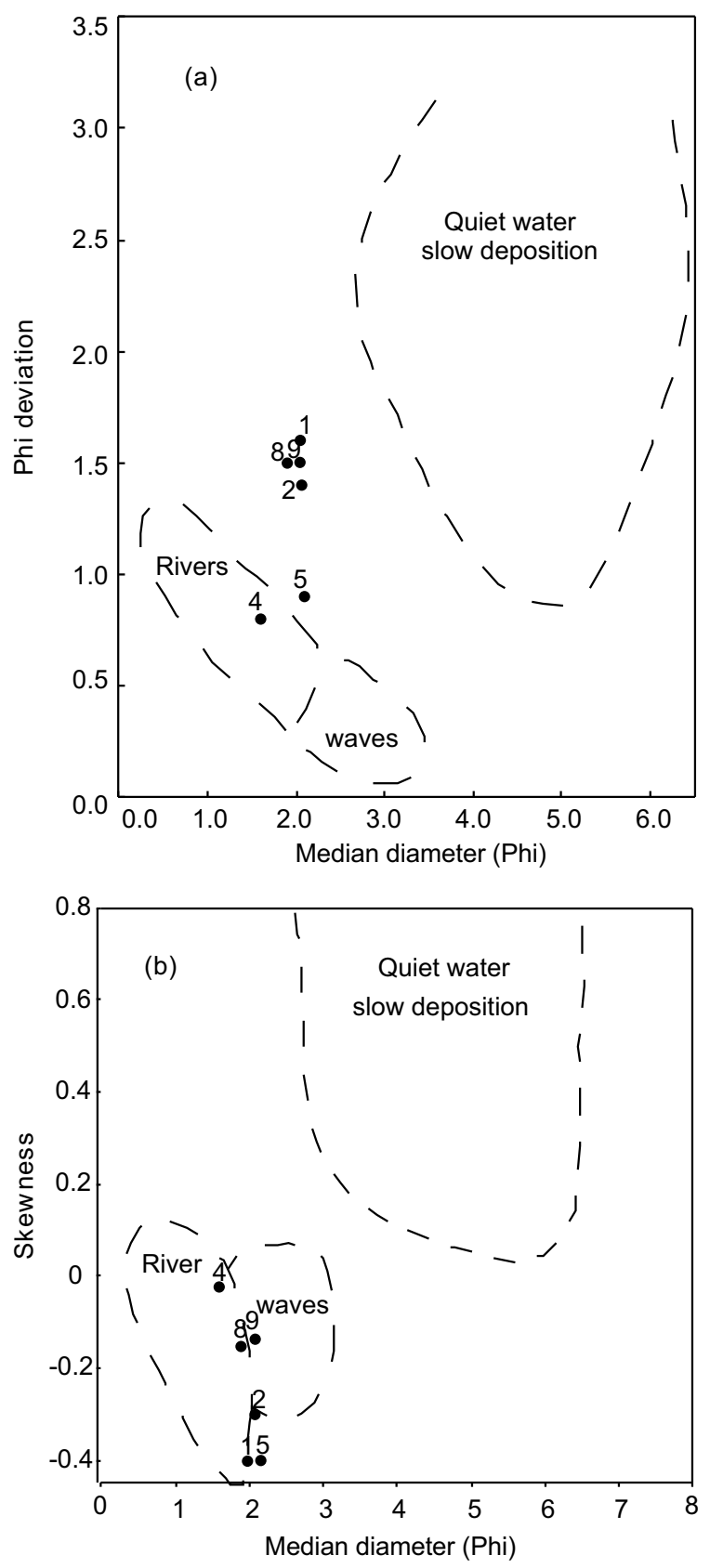

Fig. 6. Bivariate plots of loosely cemented sediments of Bara formation from Lakhra west section (after Stewart, 1958).

attempt has also been made to propose a suitable classification for the Bara formation sandstones. Different basis of the classifications of sandstone have been described by many sedimentologists including Pettijohn (1975); Friedman (1961); Dott (1964) and Dickinson (1985). Folk (1957) gave a classification of sandstone based on the textural maturity. According to him the textural maturities passes sequently through 


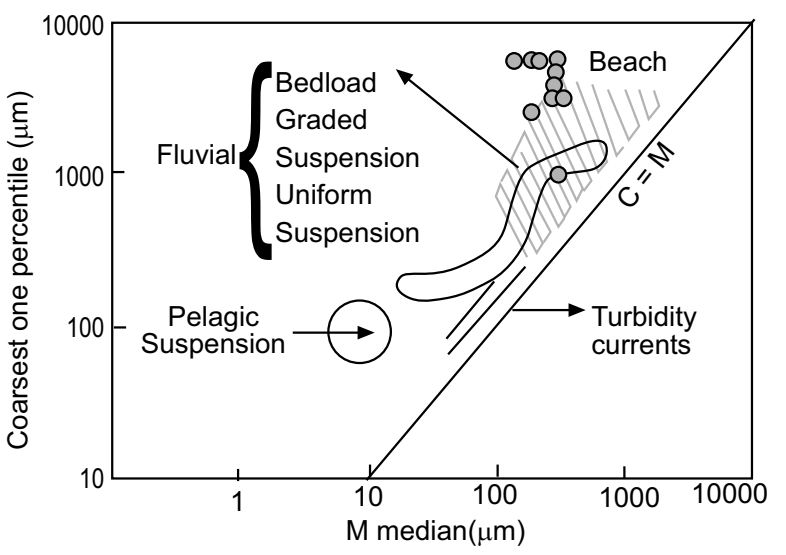

Fig. 7. Loosely cemented sediments of Bara formation of Lakhra section diagram after Passega (1964).

the following four stages:

(1) Immature stage: sediments in this stage contain over 5 percent terrigenous clay matrix, including sand grains which are usually poorly sorted and angular.

(2) Sub mature stage: sediments contain less than 5 percent clay, but sand grains are still poorly sorted ( $\varphi$ over $0.5 \varphi$ ) and are not well rounded.

(3) Mature stage: sediments contain little or no clay, and sand grains are well sorted ( $\varphi$ under $0.5 \varphi$ ), but still not rounded.

(4) Supermature stage: sediments do not contain clay, and the sand grains are well sorted and well rounded (Waddel roundness over 0.35 ; $\rho$ over 3.0 ).

The classification of the loose cemented sandstones of Bara formation has been done on the values of the sorting stages displayed by the sand grains, which are ranging from 0.3 to $1.2 \varphi$ and shown in Table 2 . These values indicated that the studied sandstones are mixture of well sorted; moderately well sorted and poorly sorted grains which suggested that these sandstones belong to the sub mature to mature stages. The sub maturity and maturity of the studied sandstones also indicated that the energy of the medium of transportation was ranging between low to high. The sandstones of Lakhra west section, showed the range of sorting from 0.8-1.6, indicating that these are poorly to moderately sorted and are sub mature. Further, it also indicated that the sandstones were deposited under the low energy and fluvial condition of the deposition. The results of Lakhra east section indicated the sub- mature to mature stages of the sandstone which were deposited under the low high energy depositional environment.

\section{Conclusion}

Considering the above discussion, this study may be concluded as under:

The sediments of the Bara formation from the Lakhra east and west sections are composed of friable loose cemented sandstone and shales, displaying a variety of colours.

The grain sizes of the studied sediments ranges from coarse grained to medium grained and from medium grained to fine grained.

Plots of the cumulative curves of the studied samples indicated that during the deposition of studied sediments, the sorting of sedimentary grains was variable, and the sediments were deposited under the river/beach and fluvial environments.

The inclusive graphic standard deviation diagrams indicated that sediments were heterogeneous, composed of fine medium grains and were deposited under the high energy condition and fluviatile environments.

Studied sediments have been grouped into two groups; comprising the sediments from the upper lagoon and river; and the sediments from the dead end marsh channels from the upper parts.

The kurtosis values of the studied sediments indicated that these sediments are composed of Platykurtic, Mesokurtic and Leptokurtic groups of sediments.

Sandstones of Lakhra east section have been classified as mature to sub-mature on the basis of textural maturity, whereas the sandstones of Lakhra west section are classified as sub-mature sandstones.

The presence of abundant amounts of quartz and $\mathrm{SiO}_{2}$, in the bul-rock samples also indicated that sediments were deposited under fluviatile (river/beach) environments.

\section{Acknowledgement}

The author is grateful to the Chairman, Prof. Shamim A. Sheikh, Department of Geology, University of Karachi, for his fruitful suggestions as well as the permission of using the Sedimentological Lab facilities for the grain size analysis of the studied sediments. The author is indebted to offer his sincere thanks to Prof. 
Dr. Muhammed Atique Ahmed Baig, the research supervisor, for the guidance, encouragement and his valuable suggestions, without which it was not possible to present research findings in the shape of the present paper. The author is grateful to Prof. Dr. Sarfraz Hussain Solangi, Director, and Mashooque Ali Warar, Lecturer, Centre for Pure \& Applied Geology, University of Sindh, Jamshoro, for their moral support. The author is also thankful to Riaz Hussain, Assistant Geophysicist, Geological Survey of Pakistan, Karachi, for his help in composing the different diagrams for this paper on computer.

\section{References}

Abbas, G., Atique, M. 2005. A Brief on Coal Deposits of Sindh, Pakistan, Geological Survey of Pakistan, Special Publication, No. 27, Published by Geological Survey of Pakistan, Quetta, Pakistan.

Baqri, S.R.H. 1997. The distribution of sulphur in the coal fields of Sindh Province of Pakistan. In: European Coal Geology Technology, Geological Society Special Publication No. 125, pp. 237-243, Published by Geological Society London, UK.

Boggs, S. Jr. 1987. Principles of Sedimentology and Stratigraphy, 784 pp., Merrill Publishing Company, Columbus Ohio, USA.

Dickinson, W.R. 1985. Interpreting provenance relations from detrital modes of sandstone. In: Provenance, of Arenites, G.G. Zuffa (ed.), pp. 333-361., Dordrecht - Boston Lancaster, D. Reidel Publishing Company, USA.

Dott, R.H. 1964. Wacke, greywacke and matrix-what approach to immature sandstone classification? Journal of Sedimentary Petrology, 34: 625-632.

Duane, D.B. 1964. Significance of skewness in recent sediments, Western Pamlico Sound, North Carolina. Journal of Sedimentary Petrology, 34: 864-874.

Farshori, M.Z. 1967. Textural properties of the River Indus sediments. Sindh University Research Journal, (Science Series) 2: 67-72.

Folk, R.L. 1968. Petrology of Sedimentary Rocks, 170 pp., Austin Hempills, Texas, USA.

Folk, R.L. 1966. A review of the grain size parameters. Sedimentology, 6: 73-93.
Folk, R.L., Ward, W., 1957. Brazos river bar: a study in the significance of grain size parameters. Journal of Sedementary Petrology, 27: 3-26.

Friedman, G.M. 1979. Difference in size distributions of populations of particles among sands of various origins. Sedimentology, 26: 859-862.

Friedman, G.M. 1962. On sorting, sorting coefficients, and lognormaility of the grain size distribution of sandstone. Journal of Geology, 70: 737-753.

Friedman, G.M. 1961. Distinction between dune, beach and river sands from their textural characteristics. Journal of Sedimentary Research, 31: 514-529.

Hunting Survey Corporation, 1960. Reconnaissance Geology of Part of West Pakistan: Geodynamic, 550 pp., A Colombo Plan Cooperative Project, Government of Canada,Toronto, Canada.

Inman, D.L., Chamberlain, F.K. 1955. Particle size distribution in nearshore sediments. In: Finding Ancient Shorelines, J. L. Hough and H. W. Mearad (eds.), Society for Economic Paleontologists and Mineralogists Special Publication, No. 3, 106-129 pp.

Khan, R.A. 1998. Preliminary Studies of Sub-surface Extension of Coal Deposits Along the Flanks of Lakhra Anticline in Lakhra Quadrangle, (40 C/2) Sindh, Information Release No.369, Geological Survey of Pakistan, Quetta, Pakistan.

Khan, R.A. 1994. Geological Sequence at Mines in the Lakhra Coal Field, Dadu District, Sindh, Record 99, 230 pp., GSP, Published by Geological Survey of Pakistan, Quetta, Pakistan.

Passega, R. 1964. Grain size representation by CM patterns as a geological tool. Journal of Sedementary Petrology, 34: 830-847.

Passega, R. 1957. Texture as characteristics of clastic deposition: Bulletin of American Association Petroleum Geologists, 41: 1952-1984.

Pettijohn, F.J. 1975. Sedimentary Rocks, 628 pp., $3^{\text {rd }}$ edition, Harper \& Row, New York, USA.

Sahu, B.K. 1964. Depositional mechanisms form the size analysis of clastic sediments. Journal of Sedementary Petrology, 34: 73-83.

Selley, R.C. 1985. Ancient Sedimentary Environment, 317 pp., $3^{\text {rd }}$ edition, Cornell University Press, Ithaca, New York, USA.

Selley, R.C. 1970. Studies of sequence in sediments 
using a simple mathematical device, Q. Journal of Geological Society, 125: 557-581.

Shah, S.M.I. 2002. Lithostratigraphic Units of the Sulaiman and Kirther Province Lower Indus Basin, Pakistan, GSP Record No. 107, 62 pp., Geological Survey of Pakistan, Quetta, Pakistan.

Shah, S.M.I. 1977. Stratigraphy of Pakistan, Memoirs of the Geological Survey of Pakistan, No. 12, 138 pp., Geological Survey of Pakistan, Quetta, Pakistan. Shah, A.A. 1988. Coal Exploration Drilling Project Lakhra, Sindh (First Phase), Information Release
No.376, 205 pp., Geological Survey of Pakistan, Quetta, Pakistan.

Stewart, H.B. 1958. Sedimentary reflections of depositional environment in San Miguel Lagoon, Baja California, Mexico, Bulletin of the American Association of Petroleum Geologists, 42: 2567-2618.

Wadell, H. 1932. Volume, shape and roundness of rock particles. Journal of Geology, 40: 443-451.

Zingg, T. 1935. Beitrag zur Schotteranalyze. Schweizerische Mineralogische und Petrogische Mitteilungen, 15: 39-140. 